\title{
Bifurcation Analysis of an Endogenous Growth Model
}

\author{
William A. Barnett* \\ University of Kansas, Lawrence \\ and Center for Financial Stability, NY City \\ and \\ Taniya Ghosh \\ Indira Gandhi Institute of Development Research (IGIDR), Reserve Bank of India, Mumbai
}

September 23, 2013

Abstract:

This paper analyzes the dynamics of a variant of Jones (2002) semi-endogenous growth model within the feasible parameter space. We derive the long run growth rate of the economy and do a detailed bifurcation analysis of the equilibrium. We show the existence of codimension-1 bifurcations (Hopf, Branch Point, Limit Point of Cycles, and Period Doubling) and codimension-2 (Bogdanov-Takens and Generalized Hopf) bifurcations within the feasible parameter range of the model.

It is important to recognize that bifurcation boundaries do not necessarily separate stable from unstable solution domains. Bifurcation boundaries can separate one kind of unstable dynamics domain from another kind of unstable dynamics domain, or one kind of stable dynamics domain from another kind (called soft bifurcation), such as bifurcation from monotonic stability to damped periodic stability or from damped periodic to damped multiperiodic stability. There are not only an infinite number of kinds of unstable dynamics, some very close to stability in appearance, but also an infinite number of kinds of stable dynamics. Hence subjective prior views on whether the economy is or is not stable provide little guidance without mathematical analysis of model dynamics.

When a bifurcation boundary crosses the parameter estimates' confidence region, robustness of dynamical inferences from policy simulations are compromised, when conducted, in the usual manner, only at the parameters' point estimates.

Keywords: bifurcation, endogenous growth, Jones growth model, Hopf, inference robustness, dynamics, stability.

*Corresponding author: William A. Barnett, email: williamabarnett@gmail.com, tel: 1-785-832-1342, fax: 1-785-832-1527. 


\section{Introduction}

Romer (1990) proposed growth driven by technological change resulting from the research and development of profit maximizing agents. Endogenous growth models resulted. The drivers of long run growth in such models are increases in research and development intensity or investment in human capital. These models have implications for policy measures in research and development and in education.

Knowledge can be used by many people at the same time without loss. As a result, production has increasing returns to scale associated with new ideas, which, in turn, depend on population. This phenomenon is the "strong" scale effect produced by the first generation endogenous growth models of Romer (1990) and Grossman and Helpman (1991). In these models the growth rate of the economy is an increasing function of the population. As shown by Jones (1995), this result is inconsistent with United States data. Jones (2002) tries to explain these facts with a model that exhibits "weak" scale effects. Jones found that long-run growth arises from the worldwide discovery of ideas, which depend on the rate of population growth of the countries contributing to world research, rather than the level of population. Such models are often called semi-endogenous growth models.

We incorporate human capital accumulation into a Jones model. We explicitly takes into account the possibility that the investment in skill acquisition by agents might be positively, negatively, or not influenced at all by technological progress. Hence the direction of technological progress is ultimately driven by human capital investment (Bucci, 2008). Compared to Bucci (2008), we introduce the possibility of decreasing returns to scale associated with human capital and with time spent accumulating human capital in the production equation. The assumption of decreasing returns to scale is necessary to account for the scale effects in the model. Also, the introduction of such a human capital accumulation equation allows us to have a closed form solutions for the steady state of the modified model.

The next task of the paper is to examine whether the dynamics of the model change within the feasible parameter space of the model. A system undergoes bifurcation if a small, smooth change in a parameter value produces a sudden 'qualitative' or topological change in the nature of singular points and trajectories of the system. The presence of bifurcation damages the inference robustness of dynamics, when dynamical inferences are produced at point estimates of the parameters. Knowing the stability boundaries inside the feasible region of the parameter space can lead to more reliable policy simulations. 
We used the numerical continuation package, Matcont, to analyze the bifurcation scenario. We showed the existence of Andronov-Hopf, Branch Point, Limit Point of Cycles, Bogdanov-Takens, and Generalized Hopf bifurcations within the feasible parameter range of the model. Some of these results have never previously appeared in the literature on endogenous/semi-endogenous growth models.

Stability analysis is critical in understanding the dynamics of the model. Benhabib and Perli (1994) analyzed the stability properties of long-run equilibrium in the Lucas (1988) model. Arnold (2000a, b) has analyzed the stability of equilibrium in the Romer (1990) model. Arnold (2006) has done the same for the Jones (1995) model. Mondal (2008) examined the dynamics of the Grossman-Helpman (1991b) model of endogenous product cycles. The results derived in these papers provide important insights to researchers considering different policies. But a detailed bifurcation analysis has not been done so far for most of these well known endogenous and semi-endogenous growth models. The current paper aims to fill part of that gap. For example, endogenous growth theory primarily holds that the long run growth rate of an economy depends on policy measures such as subsidies for research and development or for education. A detailed knowledge of stability and bifurcation boundaries of the models can give more accurate implications of different policy measures.

As pointed out by Banerjee, Barnett, Duzhak, and Gopalan (2011), "Just as it is important to know for what parameter values a system is stable or unstable, it is equally important to know the nature of stability (e.g., monotonic convergence, damped single periodic convergence, or damped multi-periodic convergence) or instability (periodic, multi-periodic, or chaotic)". Barnett and He (1999, 2001, and 2002) examined the dynamics of the Bergstrom-Wymer continuous-time dynamic macroeconometric model of the UK economy. Both transcritical bifurcation boundary and Hopf bifurcation boundary were found. Barnett and He (2008) have estimated the singularity bifurcation boundaries within the parameter space for the Leeper and Sims (1994) model. Barnett and Duzhak (2010) found Hopf and Period Doubling bifurcations using local bifurcation analysis in a New Keynesian model. More recently, Banerjee, Barnett, Duzhak, and Gopalan (2011) examined the possibility of cyclical behavior in the Marshallian Macroeconomic Model, and Barnett and Eryilmaz (2013, 2014) investigated bifurcation in open economy models.

\section{Model Structure}

The labor endowment equation is given by 
(1) $\mathrm{L}_{\mathrm{At}}+\mathrm{L}_{\mathrm{Yt}}=\mathrm{L}_{\mathrm{t}}=\epsilon_{\mathrm{t}} \mathrm{N}_{\mathrm{t}}$,

where, at time $t, L_{t}$ is employment, $L_{Y t}$ is the labor employed in producing output, $\mathrm{L}_{\mathrm{At}}$ is the total number of researchers, and $\mathrm{N}_{\mathrm{t}}$ is the total population having rate of growth $\mathrm{n}>0$. Each person is endowed with one unit of time and divides the time among producing goods, producing ideas, and producing human capital, while $\epsilon_{\mathrm{t}}$ and $\left(1-\epsilon_{\mathrm{t}}\right)$ represent the amount of time the person spends producing output and accumulating human capital, respectively. Physical capital is accumulated by foregoing consumption.

Then

(2) $\dot{\mathrm{K}}=\mathrm{s}_{\mathrm{kt}} \mathrm{Y}_{\mathrm{t}}-\mathrm{dK} \mathrm{K}_{\mathrm{t}}, \mathrm{K}_{0}>0$,

where $s_{k t}$ is the fraction of output invested, $d$ is the exogenous, constant rate of depreciation, $Y_{t}$ is the aggregate production of homogenous final goods, and $\mathrm{K}_{\mathrm{t}}$ is capital stock. Hence, we can write

(3) $\dot{K}=Y_{t}-C_{t}-d K_{t}$.

Output is produced using the total quantity of human capital, $\mathrm{H}_{\mathrm{Yt}}$, and a set of intermediaries.

Then

(4) $H_{Y t}=h_{t} L_{Y t}$,

where $h_{t}$ is human capital per person and $L_{Y t}$ is labor employed in producing output. An individual's human capital, $\mathrm{h}_{\mathrm{t}}$, is produced by foregoing time in the labor force. Then

(5) $\dot{h_{t}}=\eta h_{t}^{\beta_{1}}\left(1-\epsilon_{t}\right)^{\beta_{2}}-\theta g_{A} h_{t}, \quad 0<\beta_{1}, \beta_{2}, \epsilon_{t}<1, \eta>0,(1+\theta)>0$,

where $\eta$ is productivity of human capital in the production of new human capital, $\theta$ reflects the effect of technological progress on human capital investment, and $\mathrm{g}_{\mathrm{A}}=\frac{\dot{A}}{A}$ is the growth rate of technology. Equation (5) builds on the human capital accumulation equation from the Uzawa-Lucas model (Uzawa, 1965 and Lucas, 1988).

Firstly, the equation is modified to show that the higher the level of human capital or time spent accumulating human capital, the more difficult it is to generate additional human capital (Gong, Greiner and Semmler, 2004). This is reflected in the equation by $0<\beta_{1}, \beta_{2}<1$. The model will exhibit strong 
scale effects, if the value of $\beta_{1}$ or $\beta_{2}$ equals 1 . An increase in the time spent for education or a higher level of human capital raises the growth rate of human capital accumulation monotonically. In turn, the balanced growth rate increases. United States data are inconsistent with those results, as shown by Jones (2002). The United States economy is fluctuating around its balanced growth path, even though educational attainment and research intensity have been steadily rising for over a decade.

Secondly, we incorporate the fact that faster technological progress, $g_{A}$, may influence the rate of human capital accumulation, which depends on the technological parameter $\theta$. We restrict $\theta>-1$ to prevent explosive or negative long run growth rates, as in Bucci (2008). Hence faster technological progress may increase, decrease, or have no effect on human capital investment. Introduction of such a human capital accumulation equation has two advantages. First, it allows us to account for the scale effects, which are usually present in endogenous growth models. Second, it makes the model tractable, and we are able to solve for possible steady states.

The production function is given by

(6) $\mathrm{Y}_{\mathrm{t}}=\mathrm{H}_{\mathrm{Yt}}^{1-\alpha} \int_{0}^{\mathrm{A}} \mathrm{x}(\mathrm{i})^{\alpha} \mathrm{di}$

where $\mathrm{x}(\mathrm{i})$ is the input of intermediate $\mathrm{i}$, and $\mathrm{A}$ is the number of available intermediates, $\alpha \in(0,1)$, and $\frac{1}{1-\alpha}$ is the elasticity of substitution for any pair of intermediates. Research and development (R\&D) enable firms to produce new intermediates. The R\&D technology is

$$
\text { (7) } \dot{\mathrm{A}}=\gamma \mathrm{H}_{\mathrm{At}}{ }^{\lambda} \mathrm{A}_{\mathrm{t}}{ }^{1-\phi}, \quad \phi>0,0<\lambda \leq 1 \text {. }
$$

According to this equation, new ideas produced at any point in time depend on the effective research effort $\left(H_{A t}\right)$ and existing stock of ideas $\left(A_{t}\right)$, while $\phi$ represents the externalities associated with $R \& D$. Then

(8) $\mathrm{H}_{\mathrm{At}}=\mathrm{h}_{\mathrm{t}} \mathrm{L}_{\mathrm{At}}$

\subsection{Final Goods Sector}

The representative final output firm rents capital goods, $x(i)$, from monopolist $i$ at price $p(i)$ and pays $\mathrm{W}$ as the rental rate for per unit of human capital. For each durable, the firm chooses a profit-maximizing quantity $\mathrm{x}(\mathrm{i})$ and $\mathrm{H}_{\mathrm{y}}$ to 


$$
\max _{x, H_{y}} \int_{0}^{\infty}\left[H_{y}^{1-\alpha} x(i)^{\alpha}-p(i) x(i)\right] d i-w H_{y}
$$

Solving the maximization problem gives

(9) $\mathrm{p}(\mathrm{i})=\alpha \mathrm{H}_{\mathrm{y}}^{1-\alpha} \mathrm{x}(\mathrm{i})^{\alpha-1}$,

$(10) \mathrm{w}=(1-\alpha) \frac{\mathrm{Y}}{\mathrm{H}_{\mathrm{y}}}$.

\subsection{Intermediate Goods Sector}

Each intermediate good $\mathrm{x}(\mathrm{i})$ is produced by a monopolist, who owns an infinitely-lived patent on a technology determining how to transform costlessly a unit of raw material $(\mathrm{K})$ into intermediate good. The production function is $x=K$. The producer of each specialized durable takes $p(i)$ as given, from equation (9), in choosing the profit maximizing output, $x$, in accordance with profit level

$$
\pi=\max _{\mathrm{x}} \mathrm{p}(\mathrm{x}) \mathrm{x}-\mathrm{rx}
$$

where ' $r$ ' is the rental price of raw capital. Solving the monopoly profit maximization problem gives

(11) $\mathrm{p}(\mathrm{i})=\overline{\mathrm{p}}=\frac{\mathrm{r}}{\alpha}$.

The flow of monopoly profit is

(12) $\pi(\mathrm{i})=\bar{\pi}=\overline{\mathrm{p}} \overline{\mathrm{x}}-\mathrm{r} \overline{\mathrm{x}}=(1-\alpha) \overline{\mathrm{p}} \overline{\mathrm{x}}$.

\subsection{The Research and Development Sector}

The decision to produce new specialized input depends on a comparison of the discounted stream of net revenue and the cost of the initial investment in a design. Because the market for designs is competitive, the price for designs, $\mathrm{P}_{\mathrm{A}}$, will be bid up until equal to the present value of the net revenue that a monopoly can extract. Hence,

$$
\text { (13) } \int_{t}^{\infty} e^{-\int_{t}^{\tau} r(s) d s} \pi(\tau) d \tau=P_{A}(t)
$$

where $\mathrm{r}$ is the interest rate. Assuming free entry into the $\mathrm{R} \& \mathrm{D}$ sector, we have the zero profit condition 
(14)

$$
w H_{A}=P_{A} \underbrace{\gamma H_{A}^{\lambda} A^{1-\phi}}_{\check{A}} \text {. }
$$

If $v(t)$ denotes the value of the innovation, then

(15) $v(t)=\int_{t}^{\infty} e^{-\int_{t}^{\tau} r(s) d s} \pi(\tau) d \tau$.

Therefore, equation (14) can equivalently be written as,

(16) $\mathrm{wH}_{\mathrm{A}}=v \gamma \mathrm{H}_{\mathrm{A}}^{\lambda} \mathrm{A}^{1-\phi}$.

Also because of symmetry with respect to different intermediates, $\mathrm{K}=\mathrm{Ax}$. The production function then is

(17) $\mathrm{Y}=\left(\mathrm{AH}_{\mathrm{Y}}\right)^{1-\alpha}(\mathrm{K})^{\alpha}$.

Hence, from equation (10) and (17),

(18) $\mathrm{w}=(1-\alpha) \mathrm{A}\left(\frac{\mathrm{K}}{\mathrm{AH}_{\mathrm{Y}}}\right)^{\alpha}$.

From zero profits in the final goods sector, $\pi=\mathrm{H}_{\mathrm{Y}}{ }^{1-\alpha} \mathrm{Ax}^{\alpha}-\mathrm{pAx}-\mathrm{wH}_{\mathrm{Y}}=0$; and from equation (10), we have

(19) $\mathrm{Y}-\mathrm{wH}_{\mathrm{Y}}=\mathrm{Apx}=\alpha \mathrm{Y}$.

Notice that wages equalize across sectors, as a result of free entry and exit.

\subsection{Consumers}

Individuals maximize intertemporal utility to choose consumption and the fraction of time devoted to human capital production (or the fraction of time devoted to market work). Hence, the agent's problem is

$$
\max _{c_{t}, \epsilon_{t}} \int_{t}^{\infty} e^{-(\rho-n) t}\left[c(\tau)^{1-\sigma}-1\right] /(1-\sigma) d t
$$

subject to

$$
\begin{gathered}
\dot{\mathrm{K}}=\mathrm{r}_{\mathrm{t}}\left[\mathrm{K}_{\mathrm{t}}+v_{\mathrm{t}} \mathrm{A}_{\mathrm{t}}\right]+\mathrm{w}_{\mathrm{t}} \mathrm{H}_{\mathrm{t}}-\mathrm{c}_{\mathrm{t}} \mathrm{N}_{\mathrm{t}}-v_{\mathrm{t}} \dot{\mathrm{A}_{\mathrm{t}}}-\dot{v}_{\mathrm{t}} \mathrm{A}_{\mathrm{t}}, \\
\dot{\mathrm{h}_{\mathrm{t}}}=\eta \mathrm{h}_{\mathrm{t}}^{\beta_{1}}\left(1-\epsilon_{\mathrm{t}}\right)^{\beta_{2}}-\theta \mathrm{g}_{\mathrm{A}} \mathrm{h}_{\mathrm{t}},
\end{gathered}
$$




$$
\text { and } \epsilon_{\mathrm{t}} \in[0,1] \text {, }
$$

where $\rho$, with $\rho>n>0$, is the subjective discount rate, and $\sigma \geq 0$ is the inverse of the intertemporal elasticity of substitution in consumption.

\section{Local Bifurcation Analysis}

Let $\mathrm{m}=\frac{\mathrm{Y}}{\mathrm{K}}$ and $\mathrm{g}=\frac{\mathrm{cN}}{\mathrm{K}}$. Using equations (11), (19), and $\mathrm{K}=\mathrm{Ax}$ implies

(20) $r=\alpha^{2} m$.

The physical capital equation can be written as,

(21) $\frac{\dot{\mathrm{K}}}{\mathrm{K}}=\mathrm{m}-\mathrm{g}-\mathrm{d}$.

As shown in the appendix, the consumers' intertemporal optimization conditions are

(22) $\frac{\dot{\mathrm{c}}}{\mathrm{c}}=\frac{\mathrm{r}-\rho}{\sigma}=\frac{\alpha^{2} \mathrm{~m}-\rho}{\sigma}$,

$\left(22^{\prime}\right)-r+\frac{\dot{h}}{h}\left(\frac{\beta_{2} L_{Y}}{(1-\varepsilon) N}+1\right)+\theta g_{A}\left(\frac{\beta_{2} L_{Y}}{(1-\varepsilon) N}-\left(1-\beta_{1}\right)\right)=\left(\beta_{2}-1\right) \frac{(-\varepsilon)}{(1-\varepsilon)}-\frac{\dot{w}}{w}-n$.

Substituting equations (20), (21), (22), and using $g=\frac{\mathrm{cN}}{\mathrm{K}}$, we can derive $\frac{\dot{\mathrm{g}}}{\mathrm{g}}=\frac{\dot{\mathrm{c}}}{\mathrm{c}}-\frac{\dot{\mathrm{N}}}{\mathrm{N}}-\frac{\dot{\mathrm{K}}}{\mathrm{K}}$, so that

(23) $\frac{\dot{g}}{\mathrm{~g}}=\left(\frac{\alpha^{2}}{\sigma}-1\right) m-\frac{\rho}{\sigma}+\mathrm{n}+\mathrm{g}+\mathrm{d}$.

Multiplying both sides of equation (1) by $\mathrm{h}_{\mathrm{t}}$, and using the equations (4) and (8), we have

$$
\text { (24) } \underbrace{\mathrm{h}_{\mathrm{t}} \mathrm{L}_{\mathrm{At}}}_{\mathrm{H}_{\mathrm{At}}}+\underbrace{\mathrm{h}_{\mathrm{t}} \mathrm{L}_{\mathrm{Yt}}}_{\mathrm{H}_{\mathrm{Yt}}}=\underbrace{h_{\mathrm{t}} \mathrm{L}_{\mathrm{t}}}_{\mathrm{H}_{\mathrm{t}}}=\mathrm{h}_{\mathrm{t}} \epsilon_{\mathrm{t}} \mathrm{N}_{\mathrm{t}}
$$

Let $\quad \mathrm{u}=\frac{\gamma}{\mathrm{A}^{\phi}} \mathrm{h} \in \mathrm{N}$ and $v=\frac{(1-\alpha) \mathrm{Y}}{\mathrm{vA}}$

Using equations (10), (16), and (24) in equation (7), $\frac{\dot{A}}{\mathrm{~A}}=\frac{\gamma \mathrm{H}_{\mathrm{A}}}{\mathrm{A}^{\phi}}$. Setting $\lambda=1$ for the rest of the analysis,

$$
\text { (25) } \frac{\dot{A}}{\mathrm{~A}}=\underbrace{\frac{\gamma}{\mathrm{A}^{\phi}} \mathrm{h} \in \mathrm{N}}_{\mathrm{u}}-\underbrace{\frac{(1-\alpha) \mathrm{Y}}{v \mathrm{~A}}}_{\mathrm{v}}
$$


The following can be shown from equation (15), while using $\pi=\frac{\alpha(1-\alpha) Y}{A}$ from equations (12) and (19):

(26) $\frac{\dot{v}}{v}=r-\frac{\pi}{v}=\alpha^{2} m-\alpha v$

Let $f=\frac{\epsilon_{t}}{\left(1-\epsilon_{t}\right)}$. Using equation (10) and (16), it can be shown that

$$
\text { (27) } \frac{\mathrm{L}_{\mathrm{Yt}}}{\left(1-\epsilon_{\mathrm{t}}\right) \mathrm{N}_{\mathrm{t}}}=\frac{1}{\left(1-\epsilon_{\mathrm{t}}\right) \mathrm{h}_{\mathrm{t}} \mathrm{N}_{\mathrm{t}}} \frac{(1-\alpha) \mathrm{Y}_{\mathrm{t}}}{\mathrm{w}_{\mathrm{t}}}=\frac{\mathrm{vf}}{\mathrm{u}} \text {. }
$$

Letting $\mathrm{z}=\frac{\eta\left(1-\epsilon_{\mathrm{t}}\right)^{\beta_{2}}}{\mathrm{~h}_{\mathrm{t}}^{1-\beta_{1}}}$, equation (5) can be written as,

(28) $\frac{\dot{\mathrm{h}}}{\mathrm{h}}=\mathrm{z}-\theta \mathrm{g}_{\mathrm{A}}$

We can derive $\frac{\dot{\mathrm{w}}}{\mathrm{w}}=\frac{\dot{v}}{v}+(1-\phi) \frac{\dot{\mathrm{A}}}{\mathrm{A}}$ from equation (16). Substitute equation (25) and (26), we get

$$
\text { (29) } \frac{\dot{\mathrm{w}}}{\mathrm{w}}=\alpha^{2} \mathrm{~m}-\alpha v+(1-\phi)(\mathrm{u}-v) \text {. }
$$

Equation (22') is simplified in the following way by using (28), (29), and (30):

$$
\text { (30) } \frac{\dot{\epsilon}}{\epsilon}=\frac{1}{\mathrm{f}\left(\beta_{2}-1\right)}\left[-\mathrm{z}-\theta \mathrm{g}_{\mathrm{A}}\left(\beta_{1}-2\right)+\alpha v-\beta_{2} \frac{\mathrm{zvf}}{\mathrm{u}}-(1-\phi)(\mathrm{u}-v)-\mathrm{n}\right] \text {. }
$$

From equation (17), we have

(31) $\mathrm{m}=\frac{\mathrm{Y}}{\mathrm{K}}=\left(\frac{\mathrm{AH} \mathrm{Y}}{\mathrm{K}}\right)^{1-\alpha}$.

Using equation (16), (18), and (31), it follows that

$$
v \gamma \mathrm{A}^{1-\phi}=\mathrm{w}=(1-\alpha) \mathrm{A}\left(\frac{\mathrm{K}}{\mathrm{AH_{Y }}}\right)^{\alpha}
$$

which implies that

$$
\mathrm{m}^{\frac{\alpha}{1-\alpha}}=\frac{(1-\alpha) \mathrm{A}^{\phi}}{v \gamma} .
$$


Substituting equations (25) and (26) into, $\frac{\dot{m}}{\mathrm{~m}}=\frac{(1-\alpha)}{\alpha}\left[-\frac{\dot{v}}{v}+\phi \frac{\dot{A}}{\mathrm{~A}}\right]$, which is derived from the above relation, we find

(32) $\frac{\dot{m}}{\mathrm{~m}}=\frac{(1-\alpha)}{\alpha}\left[-\alpha^{2} \mathrm{~m}+\alpha v+\phi(u-v)\right]$.

From equations (21) and (32) and using $\frac{\dot{\mathrm{Y}}}{\mathrm{Y}}=\frac{\dot{\mathrm{m}}}{\mathrm{m}}+\frac{\dot{\mathrm{K}}}{\mathrm{K}}$, it follows that

(33) $\frac{\dot{Y}}{\mathrm{Y}}=\frac{(1-\alpha)}{\alpha}\left[-\alpha^{2} \mathrm{~m}+\alpha v+\phi(\mathrm{u}-\mathrm{v})\right]+(\mathrm{m}-\mathrm{g}-\mathrm{d})$

Substituting results from (25), (26), and (33) into $\frac{\dot{v}}{v}=\frac{\dot{Y}}{Y}-\frac{\dot{v}}{v}-\frac{\dot{A}}{A}$, we acquire

(34) $\frac{\dot{v}}{v}=\left[(1-\alpha) \mathrm{m}+v-\mathrm{g}+\left\{\frac{(1-\alpha) \phi}{\alpha}-1\right\}(\mathrm{u}-\mathrm{v})-\mathrm{d}\right]$.

Using equation (30) in $\frac{\dot{\mathrm{z}}}{\mathrm{z}}=-\beta_{2} \mathrm{f} \frac{\dot{\epsilon}}{\epsilon}-\left(1-\beta_{1}\right) \frac{\dot{\mathrm{h}}}{\mathrm{h}}$ and $\frac{\dot{\mathrm{f}}}{\mathrm{f}}=\frac{\dot{\epsilon}}{\epsilon}(1+\mathrm{f})$, we derive

$$
\begin{aligned}
& \text { (35) } \frac{\dot{\mathrm{z}}}{\mathrm{z}}=\frac{1}{\mathrm{f}\left(\beta_{2}-1\right)}\left[-\mathrm{z}-\theta \mathrm{g}_{\mathrm{A}}\left(\beta_{1}-2\right)+\alpha v-\beta_{2} \frac{\mathrm{zvf}}{\mathrm{u}}-(1-\phi)(\mathrm{u}-v)-\mathrm{n}\right]-\left(1-\beta_{1}\right)\left(\mathrm{z}-\theta \mathrm{g}_{\mathrm{A}}\right), \\
& \text { (36) } \frac{\dot{\mathrm{f}}}{\mathrm{f}}=\frac{(1+\mathrm{f})}{\mathrm{f}\left(\beta_{2}-1\right)}\left[-\mathrm{z}-\theta \mathrm{g}_{\mathrm{A}}\left(\beta_{1}-2\right)+\alpha v-\beta_{2} \frac{\mathrm{zvf}}{\mathrm{u}}-(1-\phi)(\mathrm{u}-v)-\mathrm{n}\right] .
\end{aligned}
$$

Using equations (25), (28), (30) in $\frac{\dot{\mathrm{u}}}{\mathrm{u}}=\frac{\dot{\mathrm{h}}}{\mathrm{h}}+\frac{\dot{\mathrm{N}}}{\mathrm{N}}-\phi \frac{\dot{\mathrm{A}}}{\mathrm{A}}+\frac{\dot{\epsilon}}{\epsilon}$, we find

$$
\text { (37) } \frac{\dot{\mathrm{u}}}{\mathrm{u}}=\mathrm{z}-\theta \mathrm{g}_{\mathrm{A}}+\mathrm{n}-\phi(\mathrm{u}-\mathrm{v})+\frac{\left[-\mathrm{z}-\theta \mathrm{g}_{\mathrm{A}}\left(\beta_{1}-2\right)+\alpha v-\beta_{2} \frac{\mathrm{zvf}}{\mathrm{u}}-(1-\phi)(\mathrm{u}-v)-\mathrm{n}\right]}{\mathrm{f}\left(\beta_{2}-1\right)}
$$

Equations (23), (32), (34), (35), (36), and (37) represent the dynamic equations for the model.

\subsection{Steady State}

Definition 1. We define a steady state to be a state at which variables $g, m, v, z, f$, and $u$ grow at constant (possibly zero) rates. A steady state is a balanced growth path with zero growth rate.

Therefore, the steady state, $\mathrm{s}^{*}=\left(\mathrm{g}^{*}, \mathrm{~m}^{*}, \mathrm{v}^{*}, \mathrm{z}^{*}, \mathrm{f}^{*}, \mathrm{u}^{*}\right)$, is such that, $\dot{\mathrm{g}}=\dot{\mathrm{m}}=\dot{\mathrm{v}}=\dot{\mathrm{z}}=\dot{\mathrm{f}}=\dot{\mathrm{u}}=0$. The steady state is derived by solving the following equations. 


$$
\begin{aligned}
& \text { (38) }\left(\frac{\alpha^{2}}{\sigma}-1\right) \mathrm{m}-\frac{\rho}{\sigma}+\mathrm{n}+\mathrm{g}+\mathrm{d}=0 \\
& \text { (39) }-\alpha^{2} \mathrm{~m}+\alpha v+\phi(\mathrm{u}-v)=0 \\
& \text { (40) }(1-\alpha) \mathrm{m}+v-\mathrm{g}-\mathrm{d}+\left\{\frac{(1-\alpha) \phi}{\alpha}-1\right\}(\mathrm{u}-v)=0 \\
& \text { (41) } \mathrm{z}-\theta \mathrm{g}_{\mathrm{A}}+\mathrm{n}-\phi(\mathrm{u}-\mathrm{v})+\frac{\left[-\mathrm{z}-\theta \mathrm{g}_{\mathrm{A}}\left(\beta_{1}-2\right)+\alpha v-\beta_{2} \frac{\mathrm{zvf}}{\mathrm{u}}-(1-\phi)(\mathrm{u}-v)-\mathrm{n}\right]}{\mathrm{f}\left(\beta_{2}-1\right)}=0 \\
& \text { (42) } \frac{1}{\mathrm{f}\left(\beta_{2}-1\right)}\left[-\mathrm{z}-\theta \mathrm{g}_{\mathrm{A}}\left(\beta_{1}-2\right)+\alpha v-\beta_{2} \frac{\mathrm{zvf}}{\mathrm{u}}-(1-\phi)(\mathrm{u}-v)-\mathrm{n}\right]-\left(1-\beta_{1}\right)\left(\mathrm{z}-\theta \mathrm{g}_{\mathrm{A}}\right)=0 \\
& \text { (43) }-\mathrm{z}-\theta \mathrm{g}_{\mathrm{A}}\left(\beta_{1}-2\right)+\alpha v-\beta_{2} \frac{\mathrm{zvf}}{\mathrm{u}}-(1-\phi)(\mathrm{u}-v)-\mathrm{n}=0 .
\end{aligned}
$$

The steady state is $\left(\mathrm{z}^{*}, \mathrm{v}^{*}, \mathrm{u}^{*}, \mathrm{~m}^{*}, \mathrm{~g}^{*}, \mathrm{f}^{*}\right)$, where

$$
\begin{aligned}
& \mathrm{z}^{*}=\frac{\mathrm{n} \theta}{\phi} \\
& \mathrm{v}^{*}=\frac{\rho-\mathrm{n}}{\alpha}+\frac{\mathrm{n} \sigma}{\phi \alpha}, \\
& \mathrm{u}^{*}=\mathrm{v}^{*}+\frac{\mathrm{n}}{\phi}, \\
& \mathrm{m}^{*}=\frac{\mathrm{v}^{*}}{\alpha}+\frac{\mathrm{n}}{\alpha^{2}}, \\
& \mathrm{~g}^{*}=\left(1-\frac{\alpha^{2}}{\sigma}\right) \mathrm{m}^{*}+\frac{\rho}{\sigma}-\mathrm{n}-\mathrm{d}, \\
& \mathrm{f}^{*}=\frac{\mathrm{u}^{*}}{\mathrm{v}^{*} \beta_{2}}\left(\frac{\phi \rho}{\theta \mathrm{n}}-\frac{(\phi+1-\sigma)}{\theta}-\left(\beta_{1}-1\right)\right) .
\end{aligned}
$$

Theorem 1. A unique steady state exists, if

$$
\Lambda=(1+\phi)(\sigma-1) \mathrm{g}_{\mathrm{A}}+\rho-\mathrm{n}>0 .
$$

Proof: $\Lambda>0$ is necessary and sufficient for the transversality condition for the consumer's utility maximization problem to hold. See the appendix for the rest of the proof. 
A complete bifurcation analysis of the steady state is done in the next section. But first we briefly discuss the appearance of the path of the aggregate variables. At the balanced growth path, the aggregate variables $K, C, Y$, in accordance with the appendix, grow at the same rate given by

$$
\frac{\dot{K}}{K}=\frac{\dot{C}}{C}=\frac{\dot{Y}}{Y}=(1+\phi) g_{A},
$$

where the growth rate of technology is derived to be

$$
g_{A}=\frac{n}{\phi}
$$

\subsection{Bifurcation}

We examine the existence of codimension 1 and codimension 2 bifurcations in the dynamical system defined by equations (23), (32), (34), (35), (36), and (37). The codimension, as defined by Kuznetsov (2004), is the number of independent conditions determining the bifurcation boundary. Varying a single parameter permits us to identify codimension-1 bifurcation and varying 2 parameters permits us to identify codimension-2 bifurcation.

Andronov-Hopf bifurcation is the birth of a limit cycle from an equilibrium in the dynamical system. The equilibrium changes stability through a pair of purely imaginary eigenvalues. We use the numerical continuation package Matcont to detect such bifurcations. While some of the limit cycles generated by Andronov-Hopf bifurcation are stable (supercritical bifurcation), there could be some unstable limit cycles (subcritical bifurcation) created. Table 1 reports the values of the subjective discount rate, $\rho$, the share of human capital and the share of time devoted for the human capital production, $\beta_{1}$ and $\beta_{2}$, respectively, the effect of technological progress on human capital accumulation, $\theta$, and the depreciation rate of capital, $d$, at which Hopf bifurcation occurs, when those parameters are treated as free parameters.

A positive value of the first Lyapunov coefficient indicates creation of subcritical Hopf bifurcation. Thus for each of the cases reported in Table 1, an unstable limit cycle with periodic orbit bifurcates from the equilibrium. When $\rho, \beta_{1}, \theta$, are $d$ are treated as free parameters, a slight perturbation of them gives rise to Branch Points (Pitchfork/Transcritical bifurcations). Notice that some of the Hopf points detected are neutral saddles and are not bifurcations.

The cyclical behavior could occur for various reasons. For instance, suppose profits for a monopolist increases. As the market for designs is competitive, the price for designs, $\mathrm{P}_{\mathrm{A}}$, is bid up until it is equal to 
the present value of the net revenue that a monopoly can extract. From equation (14), wages in the R\&D sector rise. As a result of higher wages in the research sector, labor moves out of output production to the research sector. When a sufficient amount of externalities to $R \& D, 1-\phi>0$, in equation (7)) is present, the growth rate of technology $g_{A}$ starts rising. If there is a negative effect of technical progress on human capital investment so that $\theta>0$, human capital accumulation starts declining. The price of final good durables is a positive function of the average quality of labor given by equation (4) and (9). This implies that prices start falling in the final goods sector as a result of declining average quality of labor. Then monopoly profits start falling.

We further investigate the stability properties of cycles generated by different combination of such parameters. Continuation of limit cycles from the Hopf point for the case when $\rho$ is the free parameter gives rise to two Period Doubling (flip) bifurcations. Period doubling bifurcation occurs, when a new limit cycle emerges from an existing limit cycle, and the period of the new limit cycle is twice that of the old one. The initial period doubling bifurcations occur at $\rho=0.0257$ and $\rho=0.0258$ with a negative normal form coefficient indicating stable double-period cycles.

Continuing computation further from the Hopf point gives rise to Limit Point (Fold/ Saddle Node) bifurcation of cycles. From the family of limit cycles bifurcating from the Hopf point, Limit Point Cycle (LPC) is a fold bifurcation, where two limit cycles with different periods are present near LPC point at $\rho=$ 0.0258. We get another Period Doubling (flip) bifurcations upon further computation.

We carry out the continuation of limit cycles from the second Hopf point with $\theta$ treated as the free parameter. We investigate the existence of codimension-2 bifurcations by allowing two free parameters, $\theta$ and $\rho$, for the first case and $\theta$ and $\beta_{1}$ for the second. Two points were detected corresponding to codimension 2 bifurcations: Bogdanov-Takens and Generalized Hopf (Bautin) for each of the cases. At each Bogdanov-Takens point the system has an equilibrium with a double zero eigenvalue. The normal form coefficients $(a, b)$ are reported in Table 1 and are all nonzero. The Generalized Hopf points are nondegenerate, since the second Lyapunov coefficient 12 is nonzero. The Generalized Hopf (Bautin) bifurcation is a bifurcation of an equilibrium, at which the critical equilibrium has a pair of purely imaginary eigenvalues, and the first Lyapunov coefficient for the Andronov-Hopf bifucation vanishes. The bifurcation point separates branches of subcritical and supercritical Andronov- 
Hopf bifurcations in the parameter plane. For nearby parameter values, the system has two limit cycles, which collide and disappear through a saddle-node bifurcation .

\begin{tabular}{|c|c|c|}
\hline \multicolumn{3}{|c|}{ Table 1} \\
\hline Parameters Varied & Equilibrium Bifurcation & Continuation \\
\hline $\begin{array}{c}\beta_{1} \\
\text { (Figure i) } \\
\left\{\alpha=0.4, \rho=0.055, \beta_{2}=\right. \\
0.04, n=0.01, d=0, \theta= \\
0.4, \phi=1, \sigma=8\}\end{array}$ & $\begin{array}{c}\text { Branch Point (BP) } \\
\beta_{1}=1\end{array}$ & \\
\hline $\begin{array}{c}\beta_{1} \\
\text { (Figure ii) } \\
\{\alpha=0.4, \rho= \\
0.025772, \beta_{2}=0.04, n= \\
0.01, d=0, \theta=0.4, \phi= \\
0.8, \sigma=0.08\}\end{array}$ & $\begin{array}{c}\text { Hopf }(\mathbf{H}) \\
\text { First Lyapunov coefficient }= \\
0.0000230, \beta_{1}=0.19\end{array}$ & \\
\hline $\begin{array}{l}\beta_{2} \\
\left\{\alpha=0.4, \beta_{1}=0.19, \rho\right. \\
=0.025772, n=0.01, d \\
=0, \theta=0.4, \phi=0.8, \sigma \\
=0.08\}\end{array}$ & $\begin{array}{c}\text { Hopf }(\mathbf{H}) \\
\text { First Lyapunov coefficient } \\
=0.00002302, \beta_{2}=0.040000\end{array}$ & \\
\hline $\begin{array}{l}d \\
\left\{\alpha=0.4, \beta_{1}=0.19, \rho\right. \\
=0.055, \beta_{2}=0.04, n \\
=0.01, \theta=0.4, \phi=1, \sigma \\
=8\}\end{array}$ & $\begin{array}{c}\text { Branch Point (BP) } \\
\quad d=0.826546\end{array}$ & \\
\hline \multirow{5}{*}{$\begin{array}{c}\boldsymbol{\rho} \\
\text { (Figure iii) } \\
\left\{\alpha=0.4, \beta_{1}=0.19, \rho\right. \\
=0.055, \beta_{2}=0.04, n \\
=0.01, d=0, \theta=0.4, \phi \\
=1, \sigma=0.08\}\end{array}$} & Figure iii $(\mathrm{A})$ & \\
\hline & $\begin{array}{l}\text { Hopf }(\mathbf{H}) \\
\text { First Lyapunov coefficient }=\end{array}$ & $\begin{array}{c}\text { Figure iii (B): Bifurcation of Limit } \\
\text { Cycle }\end{array}$ \\
\hline & $\begin{array}{c}0.0000149 \\
\rho=0.025772\end{array}$ & $\begin{array}{c}\text { Period Doubling } \\
\text { (period }=1,569.64 ; \rho=0.0257) \\
\text { Normal form coefficient }= \\
-4.056657 \mathrm{e}-013\end{array}$ \\
\hline & & $\begin{array}{c}\text { Period Doubling } \\
\text { (period }=1,741.46 ; \rho=0.0258) \\
\text { Normal form coefficient }= \\
-7.235942 \mathrm{e}-015\end{array}$ \\
\hline & & $\begin{array}{c}\text { Limit point cycle } \\
(\text { period }=2,119.53 ; \rho=0.0258)\end{array}$ \\
\hline
\end{tabular}




\begin{tabular}{|c|c|c|}
\hline & & $\begin{array}{c}\text { Normal form coefficient= } \\
7.894415 \mathrm{e}-004\end{array}$ \\
\hline & & $\begin{array}{c}\text { Period Doubling } \\
\text { (period }=2,132.13 ; \rho=0.0258 \text { ) } \\
\text { Normal form coefficient }= \\
-1.763883 \mathrm{e}-013\end{array}$ \\
\hline & $\begin{array}{c}\text { Branch Point (BP) } \\
\rho=0.026726\end{array}$ & \\
\hline & $\begin{array}{c}\text { Hopf }(\mathbf{H}), \text { Neutral Saddle, } \\
\rho=0.026698\end{array}$ & \\
\hline & Figure iv (A) & \\
\hline $\begin{array}{c}\boldsymbol{\theta} \\
\text { (Figure iv) } \\
\left\{\alpha=0.4, \beta_{1}=0.19, \rho\right.\end{array}$ & $\begin{array}{c}\text { Hopf }(\mathbf{H}) \\
\text { First Lyapunov coefficient } \\
=0.0000230, \theta=0.400000\end{array}$ & \\
\hline $\begin{array}{l}=0.029710729, \beta_{2} \\
=0.04, n=0.01, d=0, \phi\end{array}$ & $\begin{array}{c}\text { Hopf }(\mathbf{H}) \\
\text { First Lyapunov coefficient }=\end{array}$ & $\begin{array}{c}\text { Figure iv (B): Codimension-2 } \\
\text { bifurcation }\end{array}$ \\
\hline$=.69716983, \sigma=0.08\}$ & $\begin{array}{l}0.00001973 \\
\theta=0.355216\end{array}$ & $\begin{array}{c}\text { Generalized Hopf }(\mathbf{G H}) \\
\theta=0.000044, \rho=0.580853 \\
12=(0.000001254) \\
\end{array}$ \\
\hline & & $\begin{array}{c}\text { Bogdanov-Takens (BT) } \\
\theta=0, \rho=0.644247 \\
(\mathrm{a}, \mathrm{b})=(0.000001642,-0.003441)\end{array}$ \\
\hline & & $\begin{array}{c}\text { Generalized Hopf (GH) } \\
\theta=0.000055, \beta_{\mathbf{1}}=0.584660 \\
12=0.0000008949\end{array}$ \\
\hline & & $\begin{array}{c}\text { Bogdanov-Takens }(\mathbf{B T}) \\
\theta=0, \quad \beta_{\mathbf{1}}=0.903003 \\
(\mathrm{a}, \mathrm{b})=(0.000006407790,0.03291344)\end{array}$ \\
\hline & $\begin{array}{c}\text { Hopf }(\mathbf{H}) \\
\text { Neutral saddle, } \theta=0.612624\end{array}$ & \\
\hline & $\begin{array}{c}\text { Branch Point (BP) } \\
\theta=0.613596\end{array}$ & \\
\hline
\end{tabular}


Figure (i)

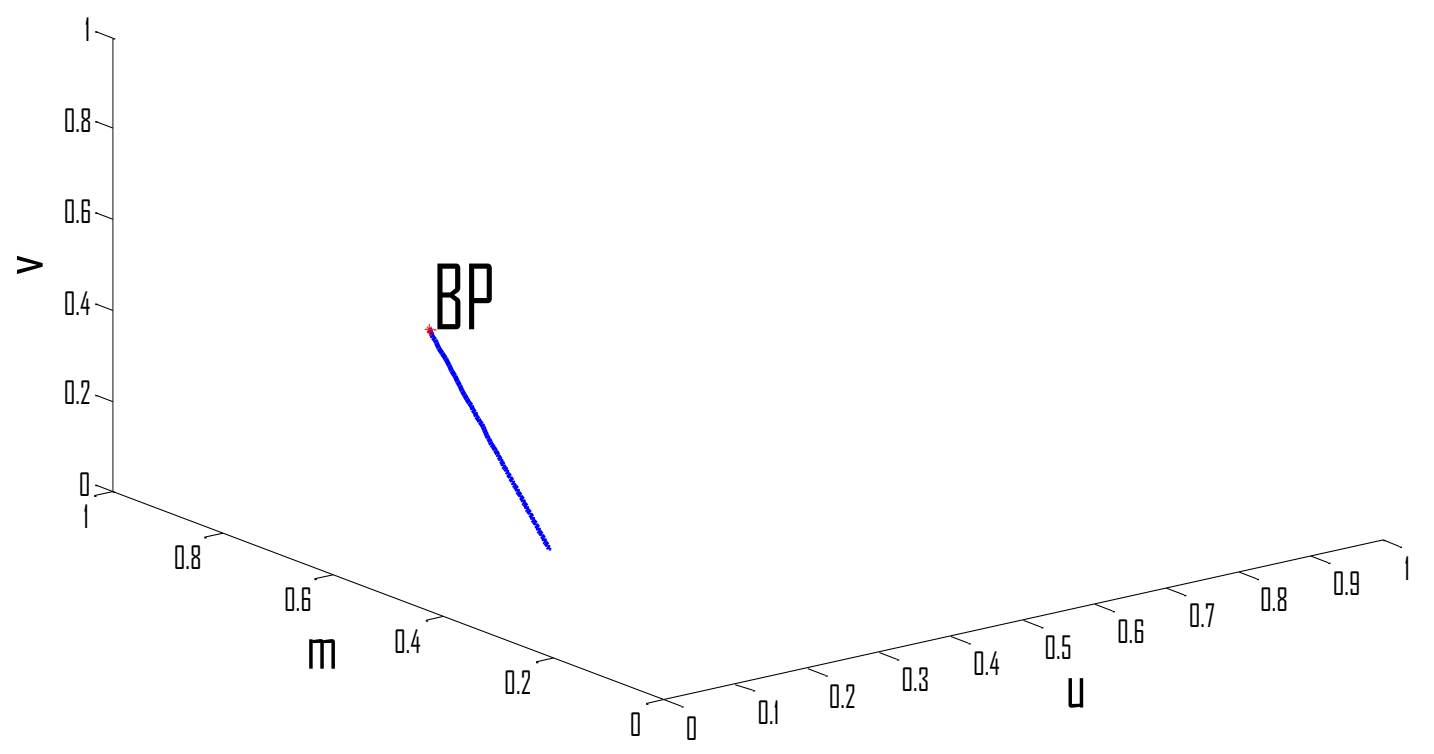

Figure (ii)

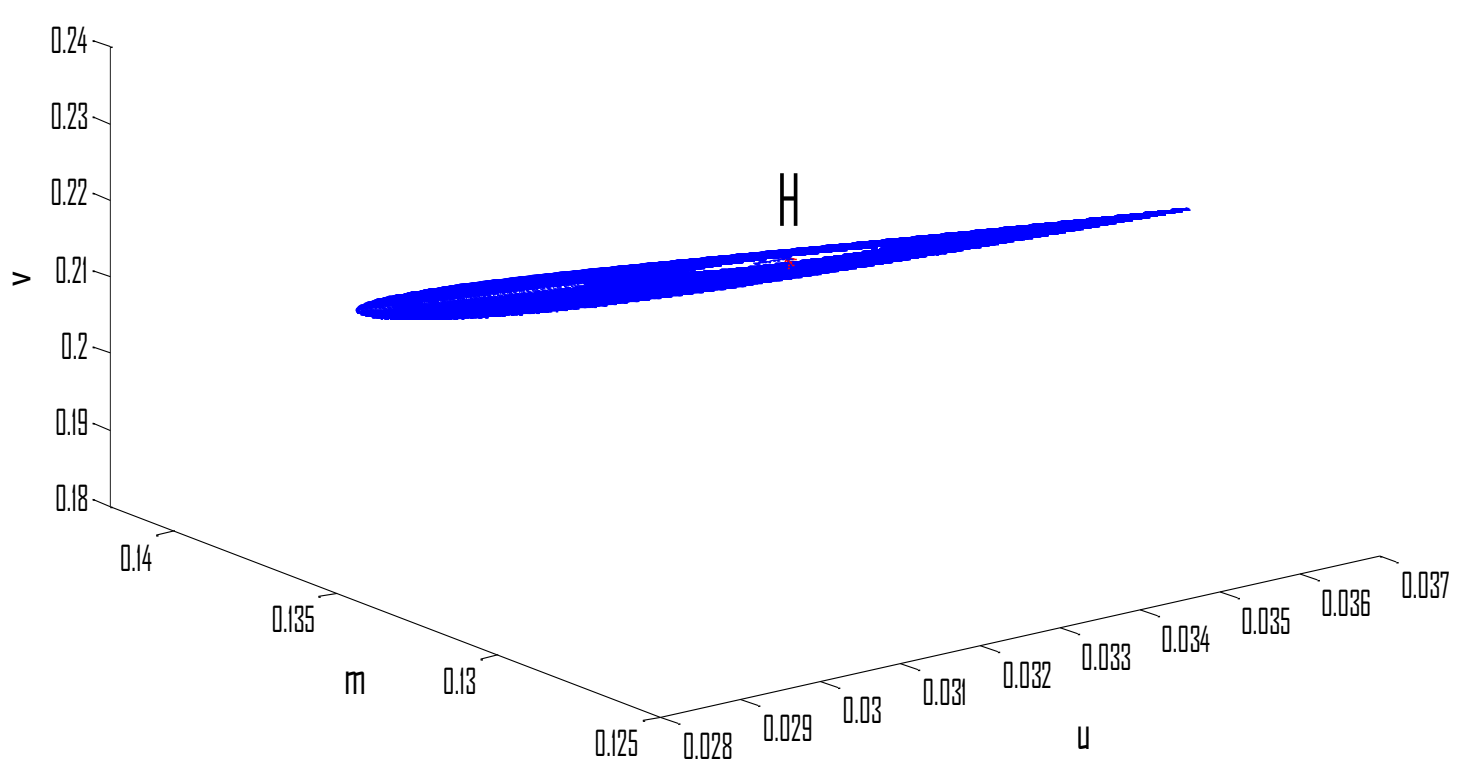

pg. 16 
Figure (iii)
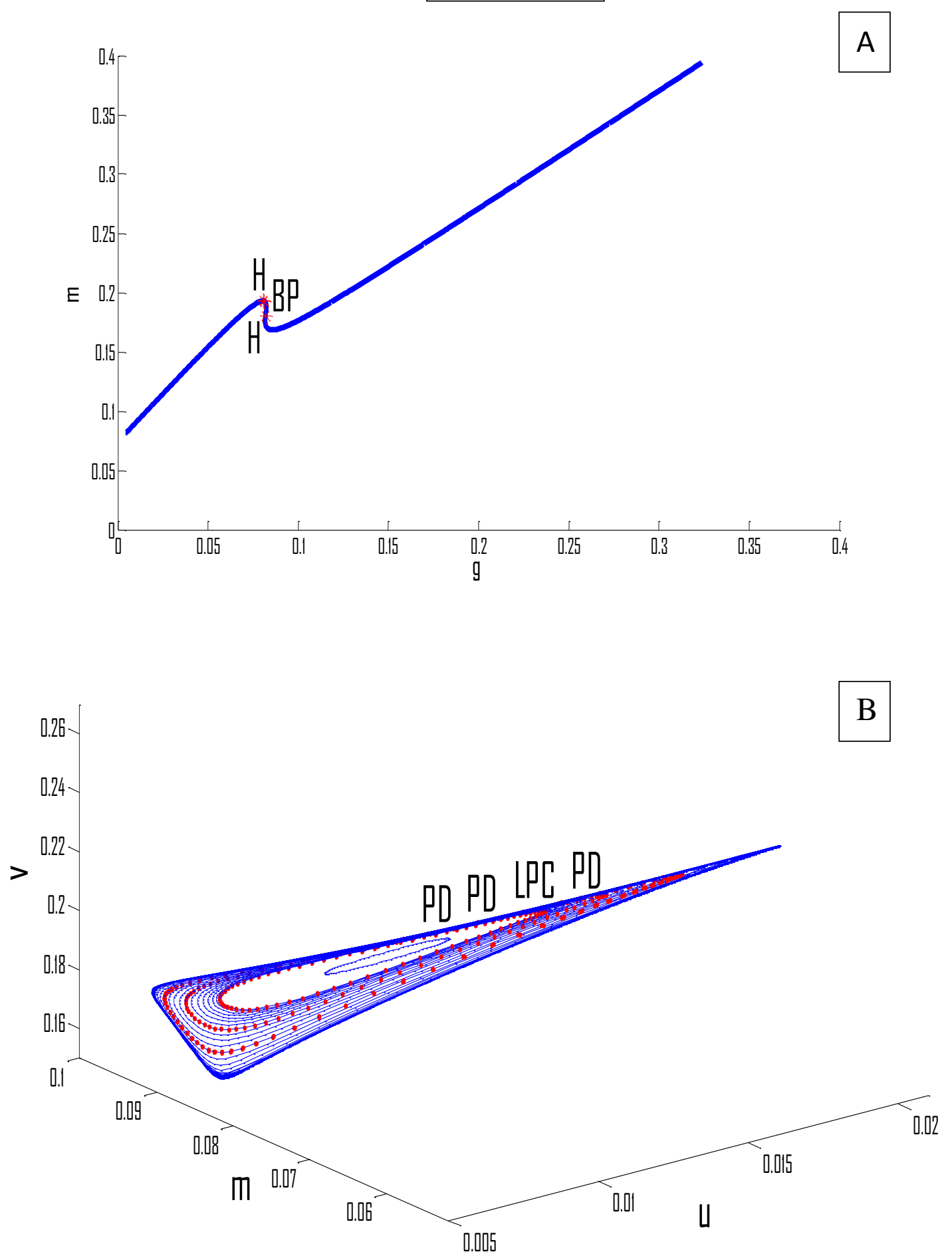

pg. 17 
Figure (iv)
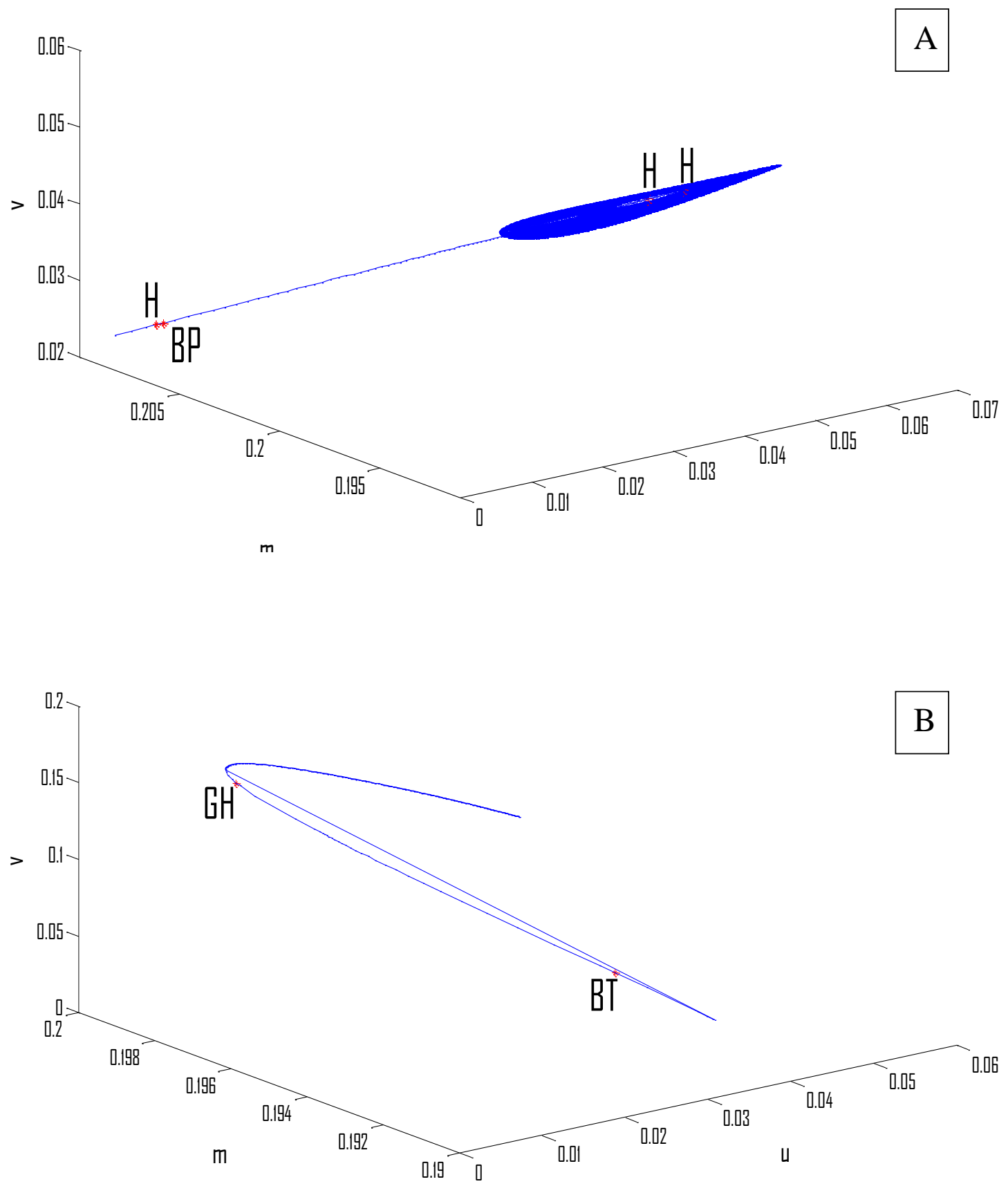

pg. 18 


\section{Conclusion}

This paper provides a detailed stability and bifurcation analysis of a modified version of the Jones model. Along the balanced growth path, we have shown that the long run growth rate of the model depends on the rate of population growth and the externality associated with R\&D. We have provided a detailed bifurcation analysis of the model's equilibrium. Several Andronov-Hopf bifurcations and Branch Points are located. Further, the stability properties of the limit cycles created from these Hopf bifurcations are examined. We showed the existence Limit Point of Cycles and Period Doubling bifurcations within the feasible parameter range of the model. These are all Codimension-1 bifurcations. Codimension-2 bifurcations like Bogdanov-Takens and Generalized Hopf are also located. The choice of certain parameters in locating various bifurcation boundaries emphasizes the role played by human capital in such a model, in which the engine of growth is technological progress, which in turn, is driven by human capital investment. The presence of this interdependent relationship, wherein the level of technological progress influences the rate of human capital accumulation, which in turn determines the growth rate of technology, creates the possibility of multitude of dynamics in the model. Hence, the parameters in the human capital accumulation among others equation play a key role in determining the dynamics of the model. It could even lead the economy to an unstable equilibrium and the balanced growth path may never be achieved.

\section{Appendix:}

We use the zero profit condition $w_{t} H_{A t}=v_{t} \dot{A}_{t}$ and equation (26), $A_{t} \dot{v}_{t}=A_{t} r_{t} v_{t}-A_{t} \pi_{t}$, in the wealth accumulation equation of the households, $\dot{K}=r_{t}\left[K_{t}+v_{t} A_{t}\right]+w_{t} H_{t}-c_{t} N_{t}-\dot{A_{t}} v_{t}-A_{t} v_{t}$, to get

$$
\dot{K}=r_{t} K_{t}+w_{t} h_{t}\left(1-l_{h t}\right) N_{t}-c_{t} N_{t}-w_{t} h_{t} L_{A t}+A_{t} \pi_{t}
$$

The relevant Hamiltonian for the consumer's problem is

$$
\begin{aligned}
\mathcal{H}= & e^{-(\rho-n) t}\left[c(\tau)^{1-\sigma}-1\right] /(1-\sigma)+\lambda\left[r_{t} K_{t}+w_{t} h_{t}\left(1-l_{h t}\right) N_{t}-c_{t} N_{t}-w_{t} h_{t} L_{A t}+A_{t} \pi_{t}\right]+ \\
& \mu\left[\eta h_{t}^{\beta_{1}}\left(1-\epsilon_{t}\right)^{\beta_{2}}-\theta g_{A} h_{t}\right] .
\end{aligned}
$$

The first order conditions are

$$
\text { (44) } c^{-\sigma} e^{-(\rho-n) t}=\lambda N \quad \Rightarrow \frac{\dot{c}}{c}=\frac{r-\rho}{\sigma},
$$


(45) $\varepsilon: \quad-\lambda w h N-\mu \eta h^{\beta_{1}} \beta_{2}(1-\varepsilon)^{\beta_{2}-1}=0 \quad \Rightarrow \frac{\lambda}{\mu}=\frac{\eta h^{\beta_{1}-1}(1-\varepsilon)^{\beta_{2}-1} \beta_{2}}{w N}$,

(46) $K: \lambda r=-\dot{\lambda} \quad \Rightarrow \frac{\dot{\lambda}}{\lambda}=-\mathrm{r}$,

(47) $h: \quad \lambda w \varepsilon N-\lambda w L_{A}+\mu \eta \beta_{1} h^{\beta_{1}-1}(1-\varepsilon)^{\beta_{2}}-\mu \theta g_{A}=-\dot{\mu}$.

Dividing (47) by $\mu$ and substituting (45) into it, we get,

(48) $\eta h^{\beta_{1}-1}(1-\varepsilon)^{\beta_{2}}\left[\frac{\beta_{2} L_{Y}}{(1-\varepsilon) N}+\beta_{1}\right]-\theta g_{A}=-\frac{\dot{\mu}}{\mu}$.

Now, from (45), $\frac{\dot{\lambda}}{\lambda}-\frac{\dot{\mu}}{\mu}=\left(\beta_{2}-1\right)\left(\frac{(-\dot{\varepsilon})}{(1-\varepsilon)}\right)+\left(\beta_{1}-1\right) \frac{\dot{h}}{h}-\frac{\dot{w}}{w}-n$,

and substituting (46)and (48) into it, we get

$$
-r+\frac{\dot{h}}{h}\left(\frac{\beta_{2} L_{Y}}{(1-\varepsilon) N}+1\right)+\theta g_{A}\left(\frac{\beta_{2} L_{Y}}{(1-\varepsilon) N}-\left(1-\beta_{1}\right)\right)=\left(\beta_{2}-1\right) \frac{(-\dot{\varepsilon})}{(1-\varepsilon)}-\frac{\dot{w}}{w}-n .
$$

The transversality conditions are

$$
\begin{aligned}
& \lim _{t \rightarrow \infty} \lambda_{t}\left[K_{t}+v_{t} A_{t}\right]=0, \\
& \lim _{t \rightarrow \infty} \mu_{t} h_{t}=0 .
\end{aligned}
$$

In a steady state, $\dot{g}=\dot{m}=\dot{v}=\dot{u}=\dot{f}=\dot{z}=0$. Using the fact that, in the steady state, $\frac{H_{Y}}{H}$ is constant, we can derive the following relations.

$$
\dot{g}=0 \text { and } \dot{m}=0 \text { implies } \frac{\dot{K}}{K}=\frac{\dot{c}}{c}+n=\frac{\dot{Y}}{Y}
$$

We use $\dot{z}=-\beta_{2} \frac{\dot{\epsilon}}{\epsilon} f-\left(1-\beta_{1}\right) \frac{\dot{h}}{h}=0$ and $\dot{f}=\frac{\dot{\epsilon}}{\epsilon}(1+f)=0$ to derive the following.

$$
\frac{\dot{\epsilon}}{\epsilon}=\frac{\left(-1+\beta_{1}\right)}{\beta_{2}} \frac{\dot{h}}{h}
$$

Hence $\dot{u}=\frac{\dot{h}}{h}+\frac{\dot{N}}{N}-\phi \frac{\dot{A}}{A}+\frac{\dot{\epsilon}}{\epsilon}=0$ implies $\frac{\dot{h}}{h}=\frac{\beta_{2}}{\left(1-\beta_{1}+\beta_{2}\right)}\left[\phi g_{A}-n\right]$. As a result, if follows that

$$
\frac{\dot{H}_{Y}}{H_{Y}}=\frac{\dot{H}}{H}=\frac{\dot{h}}{h}+\frac{\dot{N}}{N}+\frac{\dot{\epsilon}}{\epsilon}=\phi g_{A} .
$$




$$
\begin{gathered}
\text { From equation }(32),=\frac{Y}{K}=\left(\frac{A H_{Y}}{K}\right)^{1-\alpha} \text {. Hence, } \\
\frac{\dot{m}}{m}=(1-\alpha)\left[\frac{\dot{A}}{A}+\frac{\dot{H}_{Y}}{H_{Y}}-\frac{\dot{K}}{K}\right]=0 \text { implies, } \frac{\dot{K}}{K}=\frac{\dot{A}}{A}+\frac{\dot{H}_{Y}}{H_{Y}}=(1+\phi) g_{A} . \\
\text { Thus, } \frac{\dot{K}}{K}=\frac{\dot{C}}{C}=\frac{\dot{Y}}{Y}=(1+\phi) g_{A} .
\end{gathered}
$$

The transversality condition implies that,

$$
(1+\phi)(\sigma-1) g_{A}+\rho-n>0
$$

In the balanced growth path, $\frac{\dot{\epsilon}}{\epsilon}=0$, which implies $\frac{\dot{h}}{h}=0$. Hence, $g_{A}=\frac{n}{\phi}$

\section{References:}

Arnold, L.G., 2000a. "Stability of the Market Equilibrium in Romer's Model of Endogenous Technological Change: A Complete Characterization.”Journal of Macroeconomics 22, 69-84.

Arnold, L.G., 2000b. "Endogenous Technological Change: A Note on Stability."Economic Theory 16, 219-226.

Arnold, L G., 2006.“The Dynamics of Jones R\&D Model.”Review of Economic Dynamics 9, 143-152.

Banerjee, S., Barnett, W. A., Duzhak, E. A., and Gopalan, R., 2011.“Bifurcation Analysis of Zellner's Marshallian Macroeconomic Model.”Journal of Economic Dynamics and Control 35: 1577-1585.

Barnett, W.A. and Duzhak, E.A., 2010.“Empirical Assessment of Bifurcation Regions within New Keynesian Models, "Economic Theory 45, 99-128.

Barnett, W. A. and Eryilmaz, Unal, 2013, "Hopf Bifurcation in the Clarida, Gali, and Gertler Model," Economic Modelling 31: 401-404.

Barnett, W. A. and Eryilmaz, Unal, 2014, “An Analytical and Numerical Search for Bifurcations in Open Economy New Keynesian Models, Macroeconomic Dynamics, forthcoming.

Barnett, W. A. and He, Y., 1999. "Stability Analysis of Continuous-Time Macroeconometric Systems" Studies in Nonlinear Dynamics \& Econometrics 3, 169-188.

Barnett, W. A and He, Y., 2002. "Stabilization Policy as Bifurcation Selection: Would Stabilization Policy Work If the Economy Really Were Unstable?"Macroeconomic Dynamics 6, 713-747

Barnett, W. and He, Y., 2008. "Existence of Singularity Bifurcation in an Euler-Equations Model of the United States Economy: Grandmont Was Right.” Physica A 387, 3817-3825. 
Benhabib, J. and Perli, R., 1994, "Uniqueness and Indeterminacy on the Dynamics of EndogenousGrowth", Journal of Economic Theory 63, 113-142.

Bucci, Alberto, 2008, "Population Growth in a Model of Economic Growth with Human Capital Accumulation and Horizontal R\&D," Journal of Macroeconomics 30, 1124-1147

Gandolfo, Giancarlo, 2009, Economic Dynamics, Fourth edition, New York and Heidelburg, Springer.

Gong, G., Greiner, A., Semmler, W., 2004, “The Uzawa-Lucas Model Without Scale Effects:

Theory and Empirical Evidence," Structural Change and Economic Dynamics 15, 401-420 403.

Grossman, G. and Helpman, E., 1991b, "Endogenous Product Cycles, "Economic Journal 101, 12291241.

Huggett, M., Ventura, G., Yaron, A., March 2006, "Human Capital and Earnings Distribution Dynamics," Journal of Monetary Economics, Elsevier, Volume 53(2), pp264-290.

Jones, Charles I., March 2002, "Sources of U.S. Economic Growth in a World of Ideas," The American Economic Review, Volume 92 No. 1, pp 220-239.

Jones, Charles I., Aug., 1995, "R\&D-Based Models Economic Growth in a World of Ideas," Journal of Political Economy, Volume 103, Issue 4, pp 759-784

Kuznetsov, Yu.A. 1998, Elements of Applied Bifurcation Theory, 2nd edition, Springer-Verlag, New York (1998).

Mankiw, N. Gregory, Romer, David, and Weil, David N., 1992, "A Contribution to the Empirics of Economic Growth,” Quarterly Journal of Economics, 107(2), pp. 407-37

Mondal, Debasis, 2008, "Stability Analysis of the Grossman-Helpman Model of Endogenous Product Cycles," Journal of Macroeconomics, Volume 30(2008), pp 1302-1322.

Romer, P.M., 1990, “Endogenous Technological Change,” Journal of Political economy, Volume 98, S71-S102. 